\title{
An Investigation of University Students' Information Literacy Self-Efficacy Perceptions by Using Decision Tree Method
}

\author{
Bahar BARAN $^{1} \quad$ Fiğen ATA ${ }^{2}$
}

\begin{abstract}
This study aims to investigate how university students' information literacy self-efficacy perception is influenced by their Facebook and Wikipedia literacy levels, school year, gender, second language level and weekly Internet usage duration by using decision tree method. The researchers purposefully collected data from 2776 students from 11 faculties of Dokuz Eylul University. The first part of the data collection instrument included questions about university students' characteristics such as Wikipedia and Facebook literacy levels, school year, gender, second language level and weekly Internet usage duration. The second part was related to information literacy self-efficacy. The most important result of the study was that Facebook and Wikipedia literacy rather than university students' other characteristics were the first rank independent variables explaining information literacy self-efficacy. In addition, female students whose Wikipedia literacy level was at an advanced level were $16.4 \%$ of the sample and these students had the highest information literacy selfefficacy perception among the sample.
\end{abstract}

Keywords. Information Literacy, self-efficacy, Facebook, Wikipedia, university students, classification and decision tree.

\footnotetext{
1 Assoc. Prof. Dr., Dokuz Eylul University, Buca Faculty of Education, Computer Education and Instructional Technologies, Hasan Ali Yücel Building, Floor:3, Buca, İzmir. e-mail: bahar.baran(at)deu.edu.tr.

2 Ministry of National Education, Bornova Karacaoglan Mahallesi Ortaokulu, ICT teacher. atafigen(at)gmail.com
} 


\section{SUMMARY}

Purpose and Significance: Almost all university students in both Turkey and the world use Facebook and Wikipedia to make new friends, find previous friends, share daily life experiences and reach current information announced by instructors and peers from their university. University instructors also use these social media in education to deliver course materials among students, announce course specifications, and help to teach how students can reach up-date information. However, the results of academic use of social media showed that social media usage may cause unexpected negative results among students such as cyber bullying, problems related to privacy and inappropriate behaviors. All these considerations require researchers to conduct more studies on this field. Although the literature indicated the high relationship between social media and information science, researches in this field is still not sufficient. The current study aims to investigate how university students' information literacy self-efficacy is influenced by their Facebook and Wikipedia literacy levels, school year, gender, second language level and weekly Internet usage by using decision tree method.

Method: Accessible population of the study is 11 faculties of Dokuz Eylul University. The sample of the study $(n=2776)$ is $13.58 \%$ of the population $(\mathrm{N}=20442)$. During the data collection process, Wikipedia and Facebook skill level, school year, gender, second language level and weekly Internet usage duration were asked to the participants. Information literacy self-efficacy was measured by using the scale developed by Kurbanoğlu, Akkoyunlu and Umay (2006). The data were analyzed in two steps. In the first analysis, Facebook literacy level and the other independent variables were used to classify students based on their information literacy selfefficacy. In the second analysis, Wikipedia literacy level and the other independent variables were used to classify students based on their information literacy self-efficacy.

Results: The results indicated that Facebook and Wikipedia was the first rank variable explaining information literacy self-efficacy. Female students whose Wikipedia literacy level was at an advanced level were $16.4 \%$ of the sample and these students had the highest information literacy self-efficacy perception among the sample. 1st year students whose Wikipedia literacy level and second language level was at a basic level were $3.7 \%$ of the sample and they had the lowest information literacy self-efficacy perception. 
Discussion and Conclusions: This study revealed that there was a strong relationship between Wikipedia literacy and university students' information literacy self-efficacy. The similar relationship exists for Facebook. As a consequence, we support to use these technologies in universities since they are expected to develop university students' information literacy self-efficacy. In addition, this study showed that decision tree method let us to look in a different window to university students' information literacy self-efficacy by classifying them according to their descriptive attributes. Therefore, we suggest that other researchers use this method in their studies if they have large a sample. 



\title{
Üniversite Öğrencilerinin Bilgi Okuryazarlık Öz- Yeterlik Algısının Karar Ağacı Analizi ile İncelenmesi
}

\author{
Bahar BARAN ${ }^{3}$
}

Fiğen ATA ${ }^{4}$

\begin{abstract}
Öz. Bu araştırmada, üniversite öğrencilerinin bilgi okuryazarlığ1 öz-yeterlik algısını; Vikipedi kullanma becerisi, Facebook kullanma becerisi, sınıf seviyesi, cinsiyet, yabancı dil düzeyi ve haftalık Internet kullanım süresine göre sınıflama ve karar ağacı analizi ile incelemek amaçlanmıştır. Amaçlı örnekleme yöntemi kullanılarak Dokuz Eylül Üniversitesinin 11 fakültesinden 2776 öğrenciye ulaşılmıştır. Anketin birinci kısmında katılımcılara Vikipedi ve Facebook kullanma becerileri, sınıf seviyeleri, cinsiyetleri, yabancı dil düzeyleri ve haftalık Internet kullanım süreleri sorulmuştur. Anket formunun ikinci kısmında ise bilgi okuryazarlığı öz-yeterlik algısını ölçmek için Bilgi okuryazarlığı Öz-yeterlik Algısı ölçeği kullanılmıştır. Facebook ve Vikipedi becerileri bilgi okuryazarlığı öz-yeterlik algısı ile birinci düzeyde ilişkili çıkmıştır. Örneklemin \%16.4'ünü oluşturan ileri derecede Vikipedi kullanma becerisine sahip bayan öğrenciler en yüksek bilgi okuryazarlığı öz-yeterlik alg1 düzeyine sahip öğrencilerdir.
\end{abstract}

Anahtar Kelimeler. Bilgi okuryazarlığı, öz-yeterlik, Facebook, Vikipedi, üniversite öğrencileri, sınıflama ve karar ağacı

\footnotetext{
Doç. Dr., Dokuz Eylül Üniversitesi, Buca Eğitim Fakültesi, Bilgisayar ve Öğretim Teknolojileri Eğitimi Bölümü, Hasan Ali Yücel Binası, Kat: 3, No:308; Buca, İzmir. E-posta: bahar.baran(at)deu.edu.tr. 4 Milli Eğitim Bakanlığı, Bornova Karacaoglan Mahallesi Ortaokulu, Bilişim Teknolojileri Öğretmeni. atafigen(at)gmail.com,
} 


\section{Gíris}

Üniversite öğrencileri öğrenimleri süresince alanlarına ait özel bilgilere ihtiyaç duymakta, ancak araştırmaya başladıkları zaman farklı kaynaklarda bulunan sınırsız bilgi ile karşı karşıya kalmaktadır. Gereğinden fazla bilgi arasında kaybolmak veya elde edilen sınırlı bilgi içerisinde istenilen bilgiyi bulup kullanamamak onların meslek öğrenme sürecinde önlerine çıkacak önemli bir problem olabilir. Bu sebeple, bilgi arama sürecinde, öğrencilerin karşılarına çıkan ve ihtiyaçları olmayan fazla bilgileri elemeleri ve ihtiyaçları olan bilgiyi seçebilmeleri önemlidir (Eisenberg, 2008). Bilgi okuryazarlığı (Information Literacy) ihtiyaç duyulan bilginin bulunması, değerlendirilmesi ve etkili bir şekilde kullanılması ile ilgili gerekli bilgi ve becerileri kapsamaktadır (ACRL, 2006). Üniversite öğrencilerinin bu bilgi ve becerilere sahip olması onları derslerinde ve iş yaşamlarında daha başarılı yapabilir. Yaşam boyu öğrenmeyi hayat felsefesi olarak kabul eden bireylerin iyi birer bilgi okuryazarı oldukları görülmektedir (Bundy, 2004; Holt, Smissen \& Segrave, 2006). Cobo Romani (2009) bilgi okuryazarlığını, daha yeni kavramlar olan e-farkındalık, teknoloji okuryazarlığı, elektronik okuryazarlığ 1 ve medya okuryazarlığ 1 ile birlikte e-yeterliliğin altında yatan temel kavramlardan birisi olarak tanımlamıştır (Fernandez-Villavicencio, 2010). Bilgi okuryazarlığı, ağ okuryazarlığ okuryazarlığ1 ve görsel okuryazarlığı gibi birçok okuryazarlığın temelini oluşturmaktadır (Kurt, 2010).

Üniversite eğitimi almakta olan öğrencilerin bilgi okuryazarlığı özyeterlik algılarının araştırılması, onların eğitimleri sırasında dikkat edilmesi gereken unsurları ortaya çıkartabilme açısından önemlidir (Walton \& Hepworth, 2012). Bu makale kapsamında bilgi okuryazarlı̆̆ öz-yeterlik algısı, üniversite öğrencilerinin ihtiyaçları olan bilgiyi araması, bulması, değerlendirmesi ve kullanması sürecini başarılı olarak geçirebileceklerine yönelik kendileri ile ilgili yargıları olarak kullanılmaktadır (Bandura, 1977; ACRL, 2006).

Internet, bilgi okuryazarı olma yolunda üniversite öğrencilerine hızlı ve bedava hizmetler sunmaktadır. Öğrencilerin çevrimiçi kütüphane sistemleri, elektronik dergiler, vb. hizmetler yerine sosyal medyayı çok yoğun bir şekilde kullandıkları açıktır (Yusof, Ab Manan \& Alias, 2012). Betimsel bir çalışma, Türkiye'de üniversite öğrencilerinin \%78'inin Internet'e bağlı bilgisayar sahibi olduğunu göstermiştir (Ata, 2010). Sosyal medya kullanım oranları incelendiğinde öğrencilerin \%90'1 Vikipedi, \%89'u Facebook ve $\% 55$ 'i Blog kullanmaktadır (Baran \& Ata, 2013). Sosyal medya teknolojilerinin öğrenciler tarafindan kullanılma sıklıklarının (5'li likert tipi ölçeğe göre) ortalamaları alındığında Facebook $\left({ }_{x}^{-}=3.8\right)$ ve Vikipedi'nin $\left({ }_{x}^{-}\right.$ $=2.96)$, Blog'a $\left({ }_{x}^{-}=2.02\right)$ göre belirgin şekilde daha sık kullanıldığ 1 görülmektedir (Baran \& Ata, baskıda). 
Facebook'un ve Vikipedi'nin öğrenme ortamlarında nasıl kullanılması gerektiğini araştıran ve sonuçları inceleyen araştırmalar sürerken, aynı zamanda bu teknolojilerin kullanımından doğan olumsuz sonuçları araştıran çalışmalarda bulunmaktadır. Bu çalışmaları takip etmek sosyal medya ve bilgi okuryazarlığ 1 arasındaki ilişki üzerine yorum yapabilmek açısından önemlidir. Şimdiye kadar yürütülen araştırmalarda Facebook'un eğitsel kullanım alanları üniversite öğrencileri arasında ödev ve/veya ders notu paylaşımı, sınav tarihlerinin duyurulması, bilgi araştırma ve güncel bilgileri takip etme ve paylaşma şeklinde ortaya çıkmıştır (Aydın, 2012; Green \& Bailey, 2008; Tharayil \& Prince-Cohen, 2012). Vikipedi ise genelde verilen bir ödevi yapabilmek için en kolay bilgiye ulaşma aracı olarak kullanılmaktadır. Ayrıca işbirlikli şekilde bir konu hakkında makaleler oluşturmak içinde kullanılmaktadır (Konieczny, 2012; Bruscas Bellido, Serrano Mira, Romero Subirón \& Abellán Nebot, 2012). Facebook'un yoğun kullanımından doğan olumsuz sonuçlar ise uygun olmayan davranışlar sergilenmesi, kötüye kullanma, mahremiyet ve arkadaşlıklarla ilgili problemler (Aydin, 2012) ve sanal zorbalık (Aydin, 2012; Kwan \& Skoric, 2013) şeklinde ortaya çıkmıştır. Ayrıca, ödev yaparken Facebook üzerinden anında mesaj servisini kullanan öğrencilerin aynı anda birden fazla işi yapmaları (çoklu görev) sebebiyle akademik gecikme yaşayabilecekleri görülmüş̧ür (Junco \& Cotten, 2011). Eğlence amaçlı geliştirilen ortamlarda öğrenciler öğrenme ortamını yine bu amacıyla daha yoğun algılamaktadır (Baran, 2010). Vikipedi ile ilgili en büyük eleştiri, bu ortamın kullanıcılar tarafindan güncellenmesi sebebiyle her zaman doğru ve yeterli bilgiye erişilemeyeceğidir (Walling, 2012). Çevremizdeki aileleri gözlemlediğimizde, onların çocuklarına Internet erişimi sunmalarının nedeni, çocukların Internet araçlarını kullanarak daha fazla bilgiye erişmeleri ve derslerine daha fazla vakit ayırmalarını sağlamaktır. Çocukların eğlence amaçlı aşırı Internet kullanımı ise aile tarafindan ceza ve yasaklara sebep olabilmektedir (Gündüz \& Şahin, 2011).

2003 yılından sonraki "Bilgi okuryazarlığı ve Facebook" ile ilgili makaleler incelendiği zaman iki tanesinin alanyazın taraması olduğu ve farklı Web 2.0 teknolojilerinin bilgi okuryazarlı̆̆ında nasıl kullanılacağı, kütüphanecilikte web 2.0 teknolojilerinin önemi ve bilgi okuryazarlığın günümüzde bu teknolojilerle geliştirileceği anlatılmaktadır (Click \& Petit, 2010; Fernandez- Villavicencio, 2010). Yusof, Ab Manan \& Alias (2012) ise öğrencilerin yazılı çalışmalarına dönüt verebilmek için Facebook'u bir araç olarak kullanmış ve öğrencilerin birbirlerine yapıcı dönütler verebildiğini ortaya çıkartmıştır. "Bilgi okuryazarlığı ve Vikipedi" ile ilgili makalelerden birisi, nitel araştırma yöntemini kullanarak öğrencileri istekli kütüphane kullanıcıları, nadir kütüphane kullanıcıları ve kütüphaneye gitmeyenler olarak sınıflandırmıştır. Sonuçta, istekli kütüphane kullanıcısı öğrencilerin Vikpedia'yı araştırmalarının ilk adımı olarak kullandıklarını, diğer grup 
öğrencilerin ise Vikipedi'yı diğer kütüphane kaynaklarının yerine koyup çevrimiçi kaynakları kullanmayı tercih ettiklerini ortaya çıkartmıştır (ColónAguirre \& Fleming, 2012). Başka bir çalışma ise Vikipedi kullanımında cinsiyet ayrımını incelemiştir. Erkeklerin bayan öğrencilerden daha fazla Vikipedi'yı kullandığını ve bu sebeple bilgiye ulaşma yolunda daha fazla olanağa sahip olduklarını ortaya çıkartmıştır (Lim \& Kwon, 2010). Lim (2013) öğrencilere arama sırasında ipucu sunmanın ve öğrencilerin konu ile ilgili bilgisinin algılanan Vikipedi güvenirlik yargısını etkilediğini bulmuştur.

Ülkemizde yürütülen çalışmalarda bilgi okuryazarlık düzeyi ile sınıf düzeyi, yaş, cinsiyet ve teknoloji ilişkisinin incelendiği görülmüştür. Öğrencilerde, sınıf düzeyi arttıç̧a bilgi okuryazarlık düzeyi artmaktadır (Akkoyunlu \& Kurbanoğlu, 2003). Cinsiyet'in ise bilgi okuryazarlığı özyeterlik algısı ile ilişkisi bulunmamıştır (Kahyaoğlu, 2011). Bilgisayar sahipliği, bilgisayar ve/veya Internet kullanma sıklığı, bilgisayar öz-yeterlik düzeyi, Internet kullanımına yönelik tutum, ise bilgi okuryazarlığı özyeterlik algısı ile pozitif yönde güçlü ilişkilidir (Akkoyunlu \& Soylu, 2005; Akkoyunlu \& Kurbanoğlu, 2004; Demiralay \& Karadeniz, 2010; Kahyaoğlu, 2011). Ülkemizde bilgi okuryazarlı̆̆ 1 ile ilgili yürütülen çalışmalar incelendiğinde, çalışmaların genelde ilköğretim öğrencileri, öğretmen ve öğretmen adayları üzerine olduğu görülmektedir. Öğretmen ve öğretmen adayları üzerine yürütülen çalışmalar bu grup bireylerde bilgi okuryazarlığg derecesini orta ve düşük bulmuş ve yükseltilmesi için çalışmalar yapılması gerektiğini söylemektedir (Kurbanoğlu \& Akkoyunlu, 2002; Akkoyunlu \& Kurbanoğlu, 2004).

Özetle, alanyazın Facebook ve Vikipedi'nin üniversite öğrencileri arasında yoğun bir şekilde kullanıldığını göstermektedir. Bu teknolojilerin eğitimde kullanımlarına yönelik iyi örnekler mevcut olmasına rağmen, bu teknolojilerin bilinçsiz kullanımından doğan olumsuz sonuçlarda bulunmaktadır. Sosyal medya ve bilgi bilimleri arasında bir ilişki görünmesine rağmen bu alandaki çalışmaların oranı düşüktür (Aharony, 2011). Ayrıca, ülkemizde yürütülen sosyal medya çalışmaları oldukça sınırlıdır (Aydın, 2012). Alanyazın, farklı örneklemler üzerinde sınıf seviyesi, cinsiyet, yabancı dil düzeyi ve haftalık Internet kullanım süresi ile bilgi okuryazarlığı arasında ilişkiler ortaya çıkartmıştır. Bu bağlamda, üniversite öğrencileri örnekleminde Vikipedi ve Facebook kullanma becerisinin, sınıf seviyesinin, cinsiyetin, yabancı dil düzeyinin ve haftalık Internet kullanım süresinin bilgi okuryazarlığ ile ilişkisi veya bilgiye ulaşma yolunda ne tür etkileri olduğunun araştırılması önemlidir.

Sosyal bilimlerde bilimsel araştırmaların analizinde sıklıkla betimsel istatistik ya da anlam çıkartıcı istatistiksel yöntemler kullanılmaktadır. Sınıflama ve karar ağacı yöntemi ise araştırmacılara örneklemlerini bağımsız değişkenlere göre sınıflama imkanı sunmaktadır. Bu da bağımsız değişkenler 
arasında ilişki bakımından karşılaştırma yapma imkanı sunmaktadır (Gorunescu, 2011). Bu sebeple bu araştırmada, geniş bir örneklem üzerinde üniversite öğrencilerinin bilgi okuryazarlığı öz-yeterlik algısını; Vikipedi ve Facebook kullanma beceresi, sınıf seviyesi, cinsiyet, yabancı dil düzeyi ve haftalık Internet kullanım süresi değişkenlerine göre incelemek ve sınıflandırmak amaçlanmıştır.

\section{YÖNTEM}

\section{Evren ve Örneklem}

Amaçlı örnekleme yönteminin kullanıldığ bu araștırmada ulaşılabilir evren olarak Dokuz Eylül Üniversitesi öğrencileri belirlenmiştir. Üniversitenin bütün fakültelerine anket uygulanması için gerekli yasal izin yazıları gönderilmiştir. İzin belgesini onaylayan bölümlerin öğrencilerine öğretim üyeleri vasıtasıyla dersler öncesinde/sırasında veya sonrasinda ulaşılmıştır. Veri toplama işlemi tamamlandığında, elde edilen sonuçlara göre bu üniversitenin Eğitim Fakültesi, Fen Fakültesi, Edebiyat Fakültesi, Güzel Sanatlar Fakültesi, Hukuk Fakültesi, İktisadi ve İdari Bilimler Fakültesi, İlahiyat Fakültesi, İşletme Fakültesi, Mühendislik Fakültesi, Tıp Fakültesi ve Mimarlık Fakültesi'nde öğrenim görmekte olan 2776 üniversite öğrencisine ulaşıldığ 1 görülmüsstür. Elde edilen örneklem $(n=2776)$ evrenin $(\mathrm{N}=20442) \% 13.58$ 'ini oluşturmuştur. Örneklem ile ilgili ayrıntılı bilgiler Tablo 1'de sunulmuştur.

Tablo 1. Örneklemin çallş̧manın bağımsız değişkenlerine göre sinıflandırılması

\begin{tabular}{llcc}
\hline & & f & \% \\
\cline { 2 - 4 } Sınıf & 1. sınıf & 925 & 33 \\
& 2. sinıf & 922 & 33 \\
& 3. sinıf & 687 & 26 \\
& 4.sinıf ve üst sinıflar & 223 & 8 \\
Cinsiyet & Toplam & 2757 & 100 \\
\hline \multirow{3}{*}{ Kadın } & 1573 & 57 \\
& Erkek & 1180 & 43 \\
& Toplam & 2753 & 100 \\
\hline \multirow{3}{*}{ Yabancı Dil } & Zayıf & 441 & 16 \\
& Orta & 1198 & 46 \\
& İyi & 788 & 30 \\
& Çok iyi & 223 & 8 \\
& Toplam & 2650 & 100 \\
\hline
\end{tabular}




\begin{tabular}{llcc}
\hline & $0-7$ & 1167 & 42 \\
\multirow{4}{*}{ Internet kullanım süresi } & $8-21$ & 811 & 30 \\
& $22-35$ & 411 & 15 \\
& $35>$ & 368 & 13 \\
& Toplam & 2757 & 100 \\
\hline \multirow{4}{*}{ Vikipedi becerisi } & Temel & 716 & 26 \\
& Orta & 1181 & 43 \\
& İleri & 837 & 31 \\
& Toplam & 2734 & 100 \\
\hline \multirow{4}{*}{ Facebook becerisi } & Temel & 380 & 14 \\
& Orta & 789 & 29 \\
& İleri & 1537 & 57 \\
& Toplam & 2706 & 100 \\
\hline
\end{tabular}

\section{Verilerin toplanması}

Veri toplama aşamasında demografik bilgileri ve öz-yeterlik algısını soran bir anket formu kullanılmıştır. Demografik bilgiler olarak Vikipedi becerisi, Facebook becerisi, sinif seviyesi, cinsiyet, yabanci dil düzeyi, haftalık Internet kullanım süresi sorulmuştur. Vikipedi ve Facebook becerisi ileri, orta ve temel düzey olarak 3'lü likert tipi dereceleme ile ölçülmüsstür. Yabancı dil düzeyi zayıf, orta, iyi ve çok iyi şeklinde çoktan seçmeli olarak sorulmuştur. Haftalık Internet kullanım süresi ise haftada 0-7, 8-21, 22-35, 36 ve daha çok şeklinde kategorik değişken olarak sorulmuştur.

Bilgi okuryazarlığı öz-yeterlik algısını ölçmek için Kurbanoğlu, Akkoyunlu ve Umay (2006) tarafindan geliştirilen bilgi okuryazarlığı özyeterlik alg1 ölçeği kullanılmıştır. Bu ölçeğin tercih edilmesinin temel nedeni ölçeğin geliştirildiği dönem itibari ile ölçek maddelerinin geleneksel bilgi okuryazarlığı öz-yeterlik algısı ile ilgili olmasıdır. Internet’ten bilgi aramayı içeren daha güncel ölçeklerin maddeleri ile Facebook ve Vikipedi becerisinin son derecede ilişkili çıkması zaten beklenen bir sonuç olacaktır. $\mathrm{Bu}$ sebeple daha genel maddeler içeren bu ölçek tercih edilmiştir. Bilgi okuryazarlığ 1 öz-yeterlik ölçeği 7'li likert tipi bir ölçektir. Ölçek maddelerinden iki tanesi ve örnek doldurma biçimi şu şekildedir;

"Gereksinim duyduğum bilgiyi tanımlamak/açıklamak konusunda" (1) Kendime hiç güvenmiyorum, (4) Kararsızım, (7) Kendime çok güveniyorum.

"Bir araştırma ödevi yaparken bir çok kaynağı bir arada kullanmak konusunda" (1) Kendime hiç güvenmiyorum, (4) Kararsızım, (7) Kendime çok güveniyorum. 
Orijinal ölçeğin geliştirilmesi sırasında araştırmacılar ilk olarak 40 maddelik bir ölçek geliştirmiştir. Bu ölçeğin Cronbach Alfa katsayısı 0.84 olarak hesaplanmıştır. Madde analizi, Temel bileşenler analizi, varimax sonucunda ölçek 28 ve 17 maddeden oluşan iki forma dönüştürülmüştür. 28 maddeden oluşan ölçeğin alfa değeri 0.92 olarak bulunmuş ve öz-yeterliliği daha iyi ölçtüğüne karar verilmiştir. Bu çalışmada bu ölçeğin 28 maddelik olan formu kullanılmıştır.

\section{Verilerin Analizi}

$\mathrm{Bu}$ araştırmanın diğer araştırmalara göre en önemli farklılığı yürütülen analiz biçimindedir. Mevcut çalışmalar temel hipotez testlerini içermekte yani bağımsız değişken seviyelerine göre bilgi okuryazarlığının değişip değişmediğini incelemektedir. $\mathrm{Bu}$ araştırmada, veri madenciliğinde en popüler sinıflama tekniklerinden birisi Sinıflama ve Karar Ağacı (Classification \& Regression Tree-CART veya C\&RT) yöntemi (Gorunescu, 2011) kullanılmıştır. Bu yöntemi seçmedeki en temel sebep, bu analizin aynı anda analize giren bağımsız değişkenlerin hangi seviyede bağımlı değişken ile ilgili olacağı ve bağımsız değişkenlerin seviyelerine göre nasıl bir sınıflama olduğunu ortaya koymasıdır. Hedef gerçekleşen sınıflama sonucunda bir karara varmaktır. Sınıflama ve Karar ağaçları nesnelerin farklı kategorilere üyeliğini tahmin etmede kullanılır. Bu tekniğin en büyük avantajlarından birisi de görsel olarak bir ağaç yapısı sunmasıdır. Sınıflama ve Karar Ağaçlarında üç sınıflama yaklaşımı vardır; 1)Sınıflama Ağacı (Classification Tree-CT): Yordanan değişkenin yani sonucun bir sınıfa ait olması durumunda kullanılır; 2) Regresyon Ağac1 (Regression Tree-RT): Yordanan değişkenin sürekli değişken olması durumunda kullanılır (benzin fiyatı, evin değeri, ...vs), 3) Sinıflama ve Regresyon Ağacı: hem sınıflama hem de değişken durumunda kullanılır (Kayri \& Günüç, 2010; Gorunescu, 2011).

$\mathrm{Bu}$ araştırmanın bağımlı değişkenini bilgi okuryazarlığı öz-yeterlik algısı oluşturmaktadır. Yani öz-yeterlik algısı bağımsız değişkenler aracılığı ile araştırılacak olan değişkendir. Bağımsız değişkenler ise Vikipedi becerisi, Facebook becerisi, sınıf seviyesi, cinsiyet, yabancı dil düzeyi, haftalık Internet kullanım süresidir. Vikipedi becerisi ve Facebook becerisi bilgiye ulaşma açısından birbirinden farklılaşan sosyal medya teknolojilerinden ikisidir. Vikipedi sayesinde ansiklopedik bilgiye ulaş1lırken Facebook ile ancak sosyal ortam içerisinde ortaya çıkabilecek olan daha örtük bilgiye erişilebilir. Bilgi okuryazarlığını yordamakta bu iki değişken farklı zamanlarda analize alınmıştır. Yani Facebook ve Vikipedi becerileri farklı iki gruba atanmış ve diğer bağımsız değişkenler bunlara eşlik etmiştir. $\mathrm{Bu}$ çalışmada oluşan değişkenler, veri tipleri ve aldıkları değerler Tablo 2'de gösterildiği gibidir. 
Tablo 2. Analizde kullanılan değişkenler, veri tipleri ve aldıkları değerler

\begin{tabular}{|c|c|c|c|}
\hline Değişken türü & Değişken etiketleri & Veri tipi & Aldığı değer \\
\hline Bağımlı değişken & $\begin{array}{l}\text { Bilgi okuryazarlığ } \\
\text { öz-yeterlik algıs1 }\end{array}$ & $\begin{array}{l}\text { Sürekli } \\
\text { değişken }\end{array}$ & $1-7$ \\
\hline \multirow{5}{*}{$\begin{array}{l}\text { ANALIZ I } \\
\text { Bağımsız } \\
\text { değişkenler }\end{array}$} & Vikipedi becerisi & Kategorik & $1=$ zayıf, $2=$ orta, $3=$ ileri \\
\hline & Sınıf seviyesi & Kategorik & $\begin{array}{l}1=1 . \sin 1 f, 2=2 . \sin 1 f, 3=3 . \sin 1 f \\
4=4 . \sin 1 f\end{array}$ \\
\hline & Cinsiyet & Kategorik & $1=$ kadın, $2=$ erkek \\
\hline & Yabancı dil & Kategorik & $\begin{array}{l}1=\text { zayıf, } 2=\text { orta, } 3=\text { iyi, } 4=\text { çok } \\
\text { iyi }\end{array}$ \\
\hline & $\begin{array}{l}\text { Internet kullanım } \\
\text { süresi }\end{array}$ & Kategorik & $\begin{array}{l}1=0-7,2=8-21,3=22-35,4= \\
36>\end{array}$ \\
\hline \multirow{5}{*}{$\begin{array}{l}\text { ANALİZ II } \\
\text { Bağımsız } \\
\text { değişkenler }\end{array}$} & Facebook becerisi & Kategorik & $1=$ zayıf, $2=$ orta, $3=$ ileri \\
\hline & Sinıf seviyesi & Kategorik & $\begin{array}{l}1=1 . \sin 1 f, 2=2 . \sin 1 f, 3=3 . \sin 1 f \\
4=4 . \sin 1 f\end{array}$ \\
\hline & Cinsiyet & Kategorik & $1=$ kadın, $2=$ erkek \\
\hline & Yabancı dil & Kategorik & $\begin{array}{l}1=\text { zayıf, } 2=\text { orta, } 3=\text { iyi, } 4=\text { çok } \\
\text { iyi }\end{array}$ \\
\hline & $\begin{array}{l}\text { Internet kullanım } \\
\text { süresi }\end{array}$ & Kategorik & $\begin{array}{l}1=0-7,2=8-21,3=22-35,4= \\
36>\end{array}$ \\
\hline
\end{tabular}

Verilerin analizi iki aşamada gerçekleşmiştir. Her iki aşamada da bağımlı değişken olarak bilgi okuryazarlığı öz-yeterlik becerisi alınmıştır. Ancak birinci analizde bağımsız değişkenler olarak Vikipedi becerisi, sınıf seviyesi, cinsiyet, yabancı dil düzeyi, haftalık Internet kullanım süresi analize katılmıştır. İkinci analizde ise Facebook becerisi, sınıf seviyesi, cinsiyet, yabancı dil düzeyi, haftalık Internet kullanım süresi analize alınmıştır. Her iki analizde de bilgi okuryazarlığ öz-yeterlik algısına etki edecek bağımsız değişkenlerin hangi düzeyde etki ettiği ve nasıl sınıflandığını ortaya çıkartabilmek amacıyla Sınıflama ve Karar ağacı analizi yürütülmüştür.

\section{BULGULAR}

\section{Bilgi okuryazarlık öz-yeterlik algısı}

Karar ağacı analizine katılan 2776 öğrencinin bilgi okuryazarlığı özyeterlik algısı incelendiğinde örneklemin ortalaması 145.93 olarak ortaya 
çıkmıştır. Standart sapma ise 30.65 olarak ortaya çıkmıştır. Bu değer 28 madde olan 7'li likert tipi ölçekte ortalama 5.21 'e karş11ık gelmektedir.

\section{ANALİZ I: Bilgi okuryazarlığı öz-yeterlik algısının Vikipedi becerisi, sınıf seviyesi, cinsiyet, yabancı dil düzeyi, haftalık Internet kullanım süresi değişkenlerine göre incelenmesi}

Vikipedi becerisi, sınıf seviyesi, cinsiyet, yabancı dil düzeyi, haftalık Internet kullanım süresi bağımsız değişkenlerinin analize katıldığı karar ağacı yapısında, bilgi okuryazarlığı öz-yeterlik algısını açıklayan üç düzeyli karar ağacı yapısı oluşmuştur. Birinci düzeyde, üniversite öğrencilerinin Vikipedi kullanma becerilerinin bilgi okuryazarlığı öz-yeterlik algısındaki artış ile ilişkili olduğu görülmektedir $(F(2,2773)=160.99 ; p=0.00)$. Yani, Vikipedi becerisi yordanan değişken olan bilgi okuryazarlığ 1 öz-yeterlik algısı üzerine diğer bağımsız değişkenlere göre en çok etkisi olan değişken olarak ortaya çıkmıştır (Şekil 1). Yine, karar ağacında Vikipedi becerisinin üç seviyesine göre farklı değişkenlerle ilişkiler bulunmuştur (Şekil 1).

Üniversite öğrencileri arasında Vikipedi becerisinin "ileri" olduğu seviye öğrencilerin \%30,2'sini oluşturmakta ve bu ögrenciler arasında bilgi okuryazarlığ1 öz-yeterlik algısı ortalaması genel ortalamayla karşılaştırınca 159.67'ye yükselmektedir. Karar ağacı yapısına göre ikinci düzeyde "ileri" seviyede Vikipedi kullanma becerisine sahip öğrencilerin bilgi okuryazarlığ 1 öz-yeterlik algısındaki artış cinsiyet ile önemli derecede ilişkili çıkmıştır $(F(1,835)=13.79 ; p=0.00)$. Vikipedi becerisinin ileri olmas1 ve cinsiyetin kadın olması durumu örneklemin \%16.4' ünü oluşturmuş ve bu grup öğrencilerin bilgi okuryazarlığ 1 seviyeleri 162.80 'e yükselmiştir. Bu düzey için bir alt ağaç yapısı oluşmamıştır. Ancak Vikipedi becerisi ileri ve cinsiyeti erkek olan öğrenciler örneklemin \%13.8'ini oluşturmuş ve bu öğrenciler arasında öz-yeterlik algısı 155.94 olarak kadınlara göre daha düşük bir puan ortaya çıkmıştır. Bu durumda ise karar ağacı üzerinde üçüncü düzey ilişki ortaya çıkmıştır. Karar ağacı yapısına göre üçüncü düzeyde "ileri" seviye Vikipedi kullanma becerisine sahip ve cinsiyeti erkek olan öğrencilerin bilgi okuryazarlığı öz-yeterlik algısındaki artış haftalık bilgisayar kullanma süresi ile önemli derecede ilişkili çıkmıştır $(F(1,380)=$ $10.476 ; p=0.04)$. Bu düzeyde ortalama Internet kullanma süresi eğer 22 saatin altında ise bilgi okuryazarlığı öz-yeterlik algıs1 150,72 puana düşmüş, 22 saatin üzerinde ise 160,49'a puana yükselmiştir.

Üniversite öğrencileri arasında Vikipedi becerisinin "orta" olduğu seviye öğrencilerin \%42.5'ini oluşturmakta ve bu öğrenciler arasında bilgi okuryazarlığ1 öz-yeterlik algısı ortalamas1 genel ortalamayla karşılaştırınca 143.87'ye düşmektedir. Karar ağacı yapısına göre, ikinci düzeyde, "orta" seviyede Vikipedi kullanma becerisine sahip öğrencilerin bilgi okuryazarlığı 
öz-yeterlik algısındaki artış yabancı dil seviyesi ile önemli derecede ilişkili çıkmıştır $(F(2,1178)=13.13 ; p=0.00)$. Vikipedi becerisinin orta olması ve yabancı dil seviyesinin iyi ve çok iyi olması durumu örneklemin \%13.7'sini oluşturmuş ve bu grup öğrencilerin bilgi okuryazarlığı seviyeleri 148.91'e yükselmiştir. Bu düzey için bir alt ağaç yapısı oluşmamıştır. Tersine, yabancı dil seviyesinin zayıf olması durumu örneklemin \%9'unu oluşturmuş ve bu öğrencilerin bilgi okuryazarlığı seviyeleri 137.19'a düşmüştür. $\mathrm{Bu}$ dil seviyesi içinde bir alt düzey karar ağacı oluşmamıştır. Orta seviyede yabancı dil seviyesine sahip öğrenciler örneklemin 19.8 'ini oluşturmuşlar ve bu dil seviyesindeki öğrenciler için bilgi okuryazarlığı düzeyi 143.40'a düşmüştür. Karar ağacı yapısına göre üçüncü düzeyde, "orta" seviyede yabancı dil bilen öğrenciler arasında haftalık Internet kullanım süresi bilgi okuryazarlığı özyeterlik algısındaki artış ile önemli derecede ilişkili çıkmıştır $(F(2,547)=$ $14.00 ; p=0.00)$. Bu düzeyde ortalama Internet kullanma süresi eğer 7 saatin altında ise bilgi okuryazarlığ 1 öz-yeterlik algıs1 137.05 puana düşmüştür. 821 saat Internet kullanan kullanıcılar için öz-yeterlik algısı puanı 145.60 olurken, 22 saatten fazla Internete bağlanan kullanıcıların öz-yeterlik algısı 152.89'a yükselmiştir.

Üniversite öğrencileri arasında Vikipedi becerisinin "temel" olduğu seviye öğrencilerin \%27.3'ünü oluşturmakta ve bu öğrenciler arasında bilgi okuryazarlığı öz-yeterlik algısı ortalaması genel ortalamayla karşılaştırınca 133.98'e düşmektedir. Karar ağacı yapısına göre; ikinci düzeyde, "temel" seviyede Vikipedi kullanma becerisine sahip öğrencilerin bilgi okuryazarllğ öz-yeterlik algısındaki artış yabancı dil seviyesi ile önemli derecede ilişkili çıkmıştır $(F(1,756)=20.17 ; p=0.00)$. Vikipedi becerisinin temel seviyede olması ve yabancı dil seviyesinin orta ve daha iyi olması durumu örneklemin \%19,8'ini oluşturmuş ve bu grup öğrencilerin bilgi okuryazarlığı seviyeleri 137.15'e yükselmiştir. Bu düzey için bir alt ağaç yapısı oluşmamıştır. Ancak Vikipedi becerisi temel ve yabancı dil seviyesi zayıf olan öğrenciler örneklemin \%7.5'ini oluşturmuş ve bu öğrenciler arasında öz-yeterlik algıs1 125.61'e kadar düşmüştür. Bu durumda ise karar ağac1 üzerinde üçüncü düzey ilişki ortaya çıkmıştır. Karar ağacı yapısına göre üçüncü düzeyde temel seviyede Vikipedi kullanma becerisine sahip ve yabancı dil seviyesi zayıf olan öğrencilerin bilgi okuryazarlığı öz-yeterlik algısındaki artış sınıf seviyesi ile önemli derecede ilişkili çıkmıştır $(F(1,206)=11.83 ; p=0.02)$. $\mathrm{Bu}$ düzeyde sınıf seviyesi iki ve daha üst ise bilgi okuryazarlığ 1 öz-yeterlik algıs1 133.372 e yükselmiş, birinci sınıf öğrenciler için ise 117.85 puana düşmüştür. 


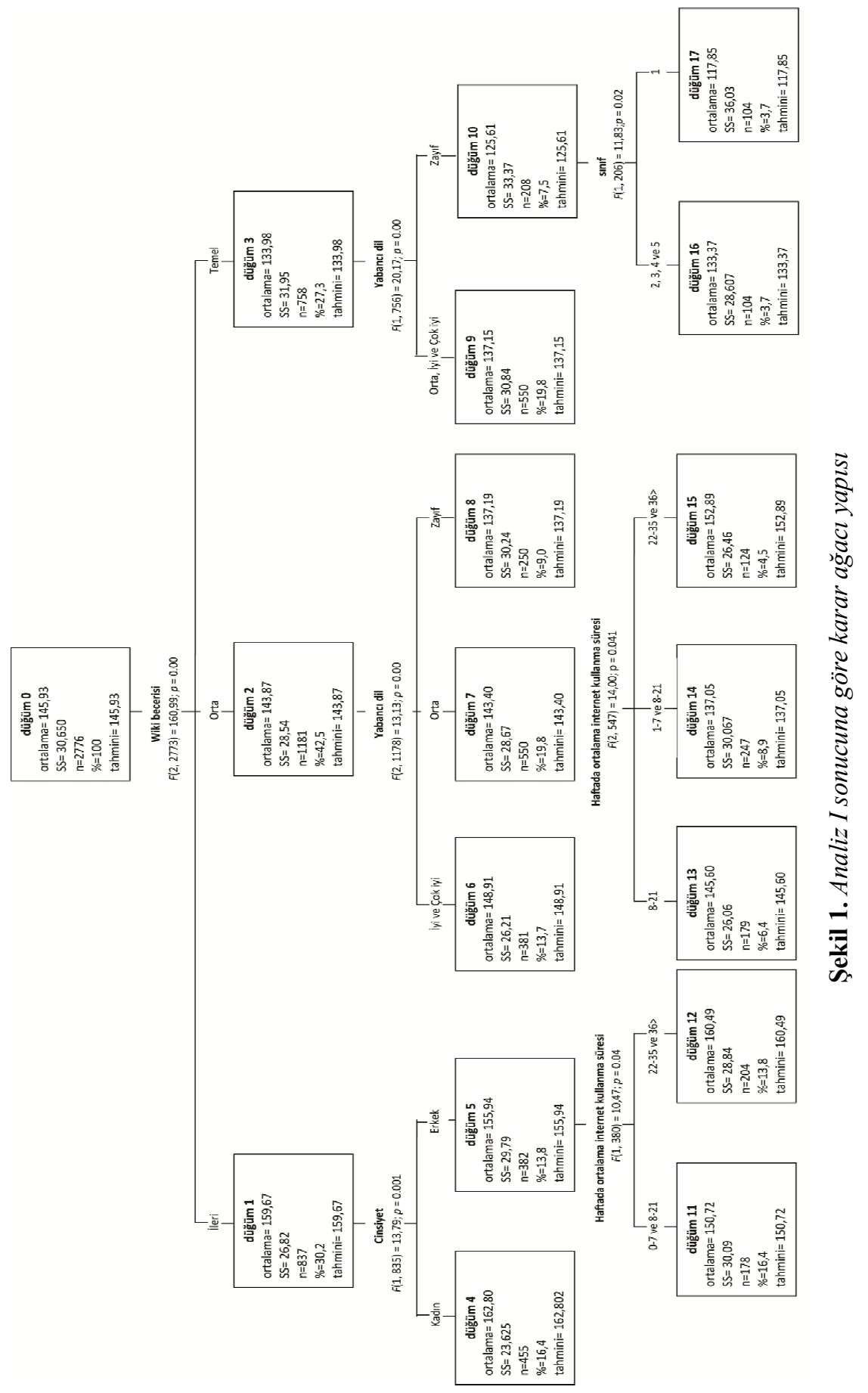




\section{ANALİZ II: Bilgi okuryazarlığı öz-yeterlik algısının Facebook becerisi, sınıf seviyesi, cinsiyet, yabancı dil düzeyi, haftalık Internet kullanım süresi değişkenlerine göre incelenmesi}

Facebook becerisi, sınıf seviyesi, cinsiyet, yabancı dil düzeyi, haftalık Internet kullanım süresi bağımsız değişkenlerinin aynı anda analize katıldığı karar ağacı yapısında, bilgi okuryazarlığı öz-yeterlik algısını açıklayan üç düzeyli karar ağacı yapısı oluşmuştur. Facebook becerisi yordanan değişken olan bilgi okuryazarlığı öz-yeterlik algısı üzerine diğer bağımsız değişkenlere göre en çok etkisi olan değişken olarak ortaya çıkmıştır (Şekil 2). Birinci düzeyde, üniversite öğrencilerinin Facebook kullanma becerileri düzeylerinin bilgi okuryazarlığı öz-yeterlik algısındaki artışla ilişkili olduğu ortaya çıkmıştır $(F(1,2773)=157.02 ; p=0.00)$. Buna göre, karar ağacında Facebook becerisinin iki düzeyine göre farklı değişkenlerle ilişkiler bulunmuştur (Şekil 2).

Üniversite öğrencileri arasında Facebook becerisinin "ileri” olduğu seviye öğrencilerin \%57.9'unu oluşturmakta ve bu öğrenciler arasında bilgi okuryazarlığ1 öz-yeterlik algısı ortalamas1 genel ortalamayla karşılaştırınca 151.98 'e yükselmektedir. Karar ağacı yapısına göre ikinci düzeyde "ileri" seviyede Facebook kullanma becerisine sahip öğrencilerin bilgi okuryazarlığı öz-yeterlik algısındaki artış yabancı dil ile önemli derecede ilişkili çıkmıştır $(F(1,1604)=21.37 ; p=0.00)$. Facebook becerisinin ileri olması ve yabancı dil seviyesinin iyi ve çok iyi olması durumu örneklemin \%24.5'ini oluşturmuş ve bu grup öğrencilerin bilgi okuryazarlığı seviyeleri 156.35 'e yükselmiştir. Bu düzey için bir alt ağaç yapısı oluşmamıştır. Facebook becerisi ileri ve yabancı dil seviyesi zayıf olan öğrenciler örneklemin \%6.7'sini oluşturmuş ve bu öğrenciler arasında öz-yeterlik algısı 142.01 olarak ortaya çıkmıştır. Bu düzey için bir alt ağaç yapısı oluşmamıştır. Ancak Facebook becerisi ileri ve yabancı dil seviyesi orta olan öğrenciler örneklemin \%26.7'sini oluşturmuş ve bu öğrenciler arasında özyeterlik algısı 150.47 olarak ortaya çıkmıştır. Bu durumda ise karar ağacı üzerinde üçüncü düzey ilişki ortaya çıkmıştır. Karar ağacı yapısına göre üçüncü düzeyde "ileri" seviyede Facebook kullanma becerisine sahip ve yabancı dil seviyesi orta olan ögrencilerin bilgi okuryazarlığı öz-yeterlik algısındaki artış haftalık bilgisayar kullanma süresi ile önemli derecede ilişkili çıkmıştır $(F(1,738)=12.89 ; p=0.00)$. Bu düzeyde ortalama Internet kullanma süresi eğer 7 saatin altında ise bilgi okuryazarlı̆̆ 1 öz-yeterlik algısı 144.71 puana düşmüş, 8-35 saat arasında ise 151.51 puan olarak ortaya çıkmış ve 36 ve üzeri saat ise 160.39 puana yükselmiştir.

Üniversite öğrencileri arasında Facebook becerisinin "temel ve orta" olduğu seviye öğrencilerin \%42.1'ini oluşturmakta ve bu öğrenciler arasında 
bilgi okuryazarlığ1 öz-yeterlik algısı ortalamas1 genel ortalamayla karşılaştırınca 137.61'e düşmektedir. Karar ağacı yapısına göre ikinci düzeyde, "temel ve orta" seviye Facebook kullanma becerisine sahip öğrencilerin bilgi okuryazarlığı öz-yeterlik algısındaki artış yabancı dil ile önemli derecede ilişkili çıkmıştır $(F(1,1166)=21.78 ; p=0.00)$. Facebook becerisinin temel ve orta olması ve yabancı dil seviyesinin iyi ve çok iyi olması durumu örneklemin \%11.9'unu oluşturmuş ve bu grup öğrencilerin bilgi okuryazarlığı seviyeleri 143.92 'ye yükselmiştir. Bu düzey için bir alt ağaç yapısı oluşmamıştır. Facebook becerisi temel ve orta ve yabancı dil seviyesi zayıf olan öğrenciler örneklemin \%9.2'sini oluşturmuş ve bu öğrenciler arasında öz-yeterlik algısı 126.95 olarak ortaya çıkmıştır. Bu düzey için bir alt ağaç yapısı oluşmamıştır. Ancak, Facebook becerisi temel ve orta ve yabancı dil seviyesi orta olan ögrrenciler örneklemin \%21'ini oluşturmuş ve bu öğrenciler arasında öz-yeterlik algısı 138.70 olarak ortaya çıkmıştır. Bu durumda ise karar ağacı üzerinde üçüncü düzey ilişki ortaya çıkmıştır. Karar ağacı yapısına göre üçüncü düzeyde, temel ve orta düzey Facebook kullanma becerisine sahip ve yabanc1 dil seviyesi orta olan öğrencilerin bilgi okuryazarlığı öz-yeterlik algısındaki artış haftalık bilgisayar kullanma süresi ile önemli derecede ilişkili çıkmıştır $(F(1,581)=$ 11.54; $p=0.02)$. Bu düzeyde ortalama Internet kullanma süresi eğer 21 saatin altında ise bilgi okuryazarlığ öz-yeterlik algısı 135 puana düşmüş, 22 saatin üzerinde ise 143.35 puana yükselmiştir. 


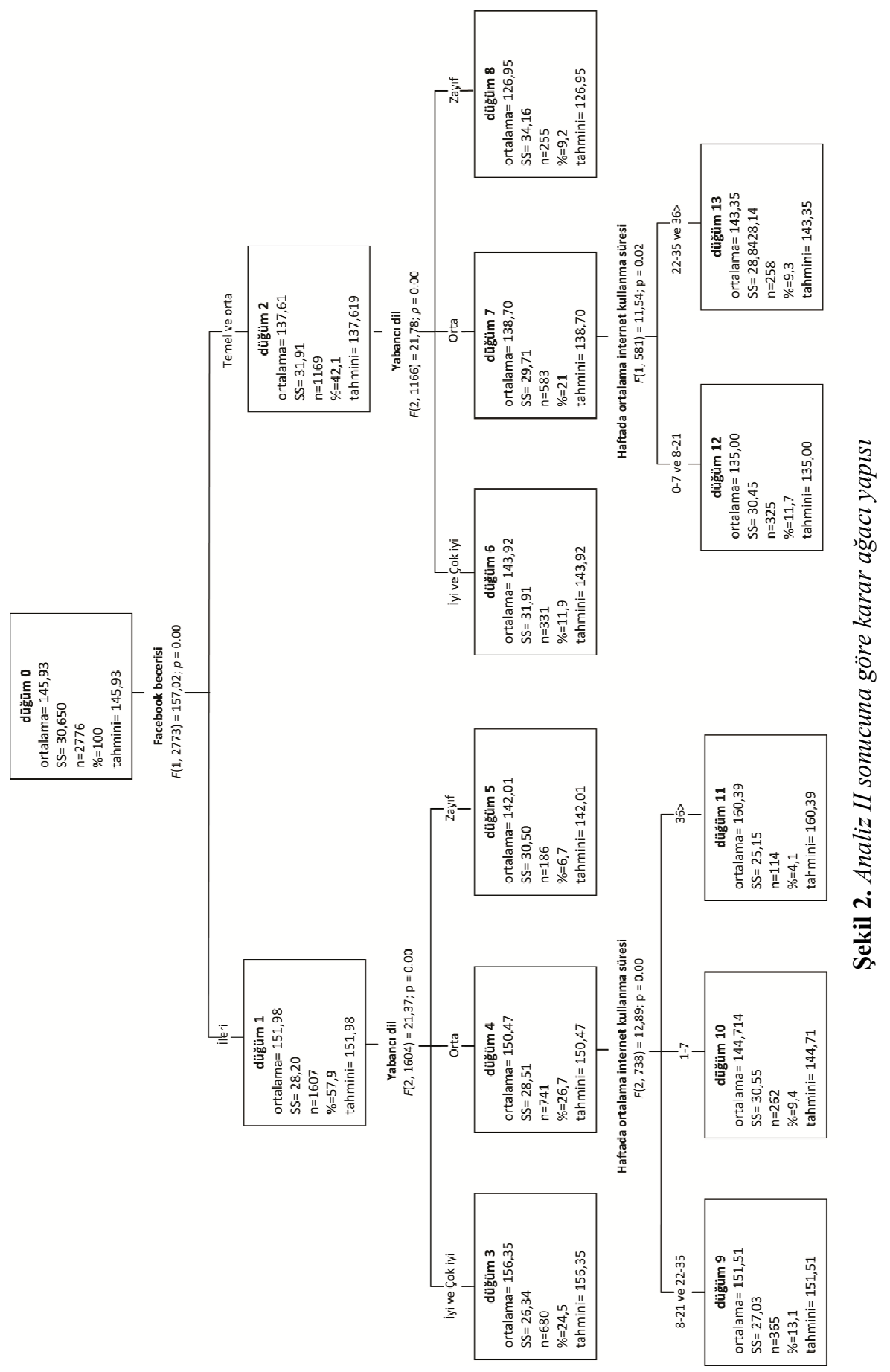




\section{TARTIŞMA VE ÖNERÍLER}

Bilgi ve iletişim teknolojilerinin gelişmesiyle birlikte eğitim ortamlarında bu teknolojilerden faydalanma düşüncesi yaygınlaşmıştır. Bilim ve teknolojinin üretildiği yerler olan yüksek öğretim kurumlarında, bu kurumların idari, kütüphane ve öğretim ortamlarındaki hizmetlerin iyileştirilmesinde teknolojinin kullanılması ise çok hızlı bir şekilde gerçekleşmiştir. Bilgi okuryazarlığı kavramı iletişim teknolojilerinin gelişmesiyle birlikte farklı bir boyut kazanmış ve bu alandaki çalışmalar büyük bir ivme kazanmıştır (Kasowitz-Scheer \& Pasqualoni, 2002; Akkoyunlu \& Kurbanoğlu, 2003; Walton \& Hepworth, 2012; Chu, \& Du, 2012). Mevcut araştırmalar bilgi okuryazarlığ yaş, bilgisayar sahipliği, sınıf seviyesi gibi faktörleri incelemiştir (Kurbanoğlu \& Akkoyunlu, 2002; Akkoyunlu \& Kurbanoğlu, 2003; Akkoyunlu \& Kurbanoğlu, 2004; Kahyaoğlu, 2011). Bu araştırma ise şimdiye kadar yürütülen araştırmalardan farklı olarak üniversite öğrencilerinin bilgi okuryazarlığ 1 öz-yeterlik algısını en çok etkileyecek değişkeni bulabilmek amaciyla Facebook ve Vikipedi kullanma becerisi, sınıf seviyesi, cinsiyet, yabancı dil düzeyi ve haftalık Internet kullanım süresi değişkenleri aynı anda analize alınarak sınıflandırma yapılmıştır.

$\mathrm{Bu}$ araştırmanın en temel sonucuna göre Facebook ve Vikipedi kullanma becerileri bilgi okuryazarlığı öz-yeterlik algısını yordama da birinci düzeyde ilişkili çıkmıştır. Ayrıca, ileri düzey Vikipedi kullanma becerisine sahip kişilerin bilgi okuryazarlığı öz-yeterlik algıları, ileri düzey Facebook kullanma becerisine sahip kişilere göre daha yüksektir. Üniversite öğrencileri arasında, Facebook kullanım sıklığının Vikipedi’ye göre daha fazla olmasına rağmen (Baran \& Ata, baskıda) Vikipedi’nin bilgi okuryazarlığını daha fazla etkilemesi bu teknolojinin sahip olduğu özellikler ve öğrenciler tarafından kullanım biçimi ile ilgili olabilir (Colón-Aguirre \& Fleming, 2012). Bu sonuç üniversite öğrencileri arasında bilgi okuryazarlığg öz-yeterlik algısını artırabilmek amaciyla Vikipedi'den daha fazla faydalanmanın önemini göstermektedir. Üniversite öğrencilerinin bilgi okuryazarlığ 1 geliştirilebilir. Üniversite öğrencilerinin buldukları kaynakları analiz, sentez ve uygulama gibi bilişsel süreçlerinden geçirerek en iyi ürünü sosyal medyanın kullanıldığı ortamda ortaya çıkarttıkları görülmüştür (Walton \& Hepworth, 2012). Bu açıdan, üniversite öğrencilerinin Vikipedi'yi ve Facebook'u eğitsel olarak nasıl daha etkili kullanabileceğine yönelik üniversite öğrencilerine danışmanlıkların verilmesi önemlidir. Ayrıca dersler içerisine kısmen entegre edilecek olan bu teknolojilerin (Baran, 2010), öğrencilerin bilgi okuryazarlığını artıracağı söylenebilir. Yüksek öğretim kurumlarının öğrencilerine sunduğu kütüphane 
hizmetlerinde sosyal medyadan faydalanmalarının önemi yadsınamaz (Hendrix, Chiarella, Hasman, Murphy, \& Zafron, 2009). Bu sonuçlar, Sosyal medyanın özellikle bilgi okuryazarlığı becerilerini kazandırmak için en kullanışlı teknolojiler olarak yorumlanmasını (Click \& Petit, 2010; Fernandez- Villavicencio, 2010; Godwin, 2009) desteklemektedir. Bu olumlu sonuçlara rağmen, biz sosyal medyanın üniversite kütüphanelerine ve derslerinde kullanımı sırasında, öğrencilerin sadece bu medyadan elde edecekleri bilgi ile sınırlı tutulmamasını ve öğrencilerin bu teknolojileri araştırmalarına destek yada başlangıç aşaması olarak kullanmalarını önermekteyiz.

$\mathrm{Bu}$ araştırmanın sağladığı önemli sonuçlardan bir diğeri örneklem içerisinde en yüksek ve en düşük bilgi okuryazarlığı öz-yeterlik algısına sahip öğrenci grubunun betimlenebilmesidir. Sonuçlara göre, Vikipedi becerisi ileri ve cinsiyeti kadın olan öğrenciler üniversite öğrencilerinin \% 16.4'ünü oluşturmakta ve bu grup öğrencilerin bilgi okuryazarlığı öz-yeterlik algısı 162.80 puan ile genel ortalamaya göre en yüksek düzeye çıkmaktadır. Vikipedi becerisi ileri ve cinsiyeti erkek olan öğrenciler üniversite öğrencilerinin \%13.8'ini oluşturmakta ve bu grup öğrencilerin bilgi okuryazarlığı öz-yeterlik algısı 155.94 puanda kalmaktadır. Bu sonuç ileri düzey Vikipedi kullanma becerisine sahip bayan üniversite öğrencilerinin erkeklerden fazla olduğunu ve bu bayanların bilgi okuryazarlığı öz-yeterlik algılarının da erkeklerden yüksek çıktığını göstermektedir. Başka bir çalışma erkek öğrencilerin bayanlara göre daha fazla Vikipedi kullanmakta olduğunu ve bu sebeple bilgiye ulaşma yolunda daha fazla olanağa sahip olduğunu söylemektedir (Lim \& Kwon, 2010). Bu çalışma erkeklerin genelde boş zaman geçirme ya da eğlence amaçlı Vikipedi’yı kullandığını göstermiştir. İki çalışma arasındaki farklılık ileri seviyede Vikipedi kullanma seviyesine sahip bayanların kullanım amaçlarının erkeklerden farklı olmasından kaynaklanmış olabilir. $\mathrm{Bu}$ durumda bu öz-yeterlik alg1 puanına sahip öğrencilerin oranlarının yükseltilmesi ve bu puanın daha da yukarı çekilmesi oldukça önemlidir. Bu noktada üniversitelerde örgün eğitim sırasında ve kütüphane hizmetlerinde Vikipedi kullanımının desteklenmesi önem taşımaktadır.

Bilgi okuryazarlığ en düşük grup ise Vikipedi kullanma becerisi temel düzeyde olan, yabancı dili zayıf olan ve 1. sınıfa devam eden öğrencilerdir. $\mathrm{Bu}$ öğrenciler örneklemin \%3.7'sini oluşturmakta ve ortalamaları 117.85 olarak ortaya çıkmaktadır. Bu sınıflamaya giren öğrenci oranlarının ise minimum tutulması önemlidir. Buna yönelik olarak üniversite içerisinde bilgi erişimine yönelik kurs ve seminerlere ek olarak, Vikipedi kullanım becerisini arttırıcı eğitimlerin sunulması ve yabancı dil düzeyinin arttırılması önemli olabilir. 
$\mathrm{Bu}$ çalışmanın diğer bir sonucu cinsiyet değişkeninin ileri derecede Vikipedi kullanma becerisine sahip kişiler için bilgi okuryazarlığını yordama da anlamlı çıkmasıdır. Cinsiyet orta ve düşük derecede Vikipedi kullanma becerisine sahip öğrencilerde anlamlı bir farklılık oluşturmamaktadır. Alanyazın geleneksel ilişkisiz örneklemler $t$-testi sonuçlarına göre bilgi okuryazarlığı öz-yeterlik algı puanında cinsiyet değişkenini ilişkili bulmamıştır (Ata, 2010; Kahyaoğlu, 2011). Karar ağacı yapısı ise öz-yeterlik algısında diğer bağımsız değişkenlere göre alt sınıflamalara bakarak ikinci düzeyde ilişki bulmayı sağlamıştır. Bu açıdan sınıflama ve karar ağacı analizinin diğer anlam çıkartıcı istatistiksel analizlere göre avantajı ortaya çıkmaktadır.

Karar ağacı yöntemini kullanarak bilgi okuryazarlı̆̆ı öz-yeterlik algısını sınıflandırma yoluyla incelemeyi sağlayan bu çalışmanın örneklem sayısının yüksek olduğu diğer eğitimsel çalışmalar için bir örnek olabileceği düşünülebilir. $\mathrm{Bu}$ açıdan eğitim araştırmalarında karar ağacı analizlerinin farklı sonuçlar ortaya çıkartacağı öngörülebilir. Bu çalışmada örneklem sayısının geniş olması bu analizin uygulanmasını ve sonuçların üniversite öğrencilerine genellenebilir olmasını sağlamıştır. Bu sebeple bundan sonra bilgi okuryazarlığı öz-yeterlik algısı üzerine çalışacak araştırmacıların bu araştırmada incelenmemiş farklı değişkenler üzerine çalışmaları yeni sonuçların ortaya çıkmasını sağlayacaktır. Ayrıca farklı hedef kitleler üzerine benzer analizlerin yürütülmesi sonuçların karşılaştırılması açısından önemli olabilir.

\section{KAYNAKLAR}

ACRL (Association of College and Research Libraries) (2006). Introduction to information literacy. Retrieved from http:/www.ala.org/acrl/issues/ infolit/overview/intro.

Aharony, N. (2011). Web 2.0 in the professional LIS literature: An exploratory analysis, Journal of Librarianship and Information Science, 43(1), 3-13.

Akkoyunlu, B,. ve Yılmaz, M. (2005). Öğretmen adaylarının bilgi okuryazarlık düzeyleri ile Internet kullanım sıklıkları ve Internet kullanım amaçları. Eurasian Journal of Educational Research, 19, 1-14.

Akkoyunlu, B., ve Kurbanoglu, S. (2004). Öğretmenlerin bilgi okuryazarlığı özyeterlik inanc1 üzerine bir çalışma. Hacettepe Üniversitesi Eğitim Fakültesi Dergisi, 27, 11-20.

Akkoyunlu, B., ve Kurbanoğlu, S. (2003). Öğretmen adaylarının bilgi okuryazarlığı ve bilgisayar öz-yeterlik algıları üzerine bir çalışma. Hacettepe Üniversitesi Eğitim Fakültesi Dergisi, 24, 1-10.

Ata, F. (2010). Üniversite ögrencilerinin web 2.0 teknolojilerini kullanim durumları ile bilgi okuryazarliğ öz-yeterlik algıları arasındaki ilişkinin incelenmesi (Yayınlanmamış yüksek lisans tezi). Dokuz Eylül Üniversitesi, Eğitim Bilimleri Enstitüsü. İzmir. 
Aydın, S. (2012). A review of research on Facebook as an educational environment. Educational Technology Research and Development, 60(6), 1093-1106.

Bandura, A. (1977). Self-efficacy: toward a unifying theory of behavioral change. Psychological Review, 84, 191-215.

Baran, B. (2010). Facebook as a formal instructional environment. British Journal of Educational Technology, 41(6), E146-E149.

Baran, B., ve Ata, F. (2013). Üniversite öğrencilerinin web 2.0 teknolojileri kullanma durumları, beceri düzeyleri ve eğitsel olarak faydalanma durumları. Eğitim ve Bilim, 38(169), 192-208.

Bruscas Bellido, G.M., Serrano Mira, J., Romero Subirón, F., \& Abellán Nebot, J. V. (2012, July). Active and cooperatıve learning in Manufacturing Engineering Using Wikipedia, the International Conference on Education and New Learning Technologies, 3316-3325.

Bundy, A. (2004). Australian and New Zealand information literacy framework: principles, standards and practice (2nd ed.). Adelaide: Australian and New Zealand Institute for information Literacy. Retrieved from http://www.library.unisa.edu.au/learn/infolit/Infolit-2nd-edition.pdf.

Chu, S. K. W., \& Du, H. S. (2012). Social networking tools for academic libraries. Journal of Librarianship and Information Science. O(0), 1-12.

Click, A., \& Petit, J. (2010). Social networking and Web 2.0 in information literacy. International Information \& Library Review, 42(2), 137-42.

Colón-Aguirre, M., \& Fleming, R. A. (2012). You just type in what you are looking for: Undergraduates' use of library resources vs. Wikipedia. The Journal of Academic Librarianship, 38(6), 391-399.

Demiralay, R. ve Karadeniz, Ş. (2010). The effect of use of information and communication technologies on elementary student teachers' perceived information literacy self-efficacy. Educational Sciences: Theory and Practice, 10(2), 841-851.

Eisenberg, M. B. (2008). Information literacy: Essential skills for the information age. Journal of Library and Information Technology, 28(2), 39-47.

Fernandez-Villavicencio, N. G. (2010). Helping students become literate in a digital, networking-based society: a literature review, and discussion. The International Information \& Library Review, 42(2), 124-136.

Godwin, P. (2009). Information literacy and Web 2.0: is it just hype? program: Electronic Library and Information Systems, 43(3), 264 - 274.

Gorunescu, F. (2011). Data mining, concepts, models and techniques. Springer, Berlin, Heidelberg.

Green, T., \& Bailey, B. (2010). Academic uses of Facebook: endless possibilities or endless perils? Techtrends, 54(3), 20-22.

Gündüz, Ş., ve Şahin, Ş. (2011). Internet usage and parents' view about Internet addiction. International Journal of Human Sciences, 8(1), 277-288.

Hendrix, J., Chiarella, D., Hasman, L. Murphy, S., \& Zafron, M. (2009). Use of Facebook in academic health sciences libraries. Journal of Medical Library Associations, 97 (1) 44-47.

Holt, D. M., Smissen, I., \& Segrave, S. (2006). New students, new learning, new environments in higher education: literacies in the digital age. Proceedings of 
the 23rd annual conference of the Australasian Society for Computers in Learning in Tertiary Education, (pp. 327-337).

Junco, R., \& Cotten, S. R. (2011). Perceived academic effects of instant messaging use. Computers \& Education, 56(2), 370-378.

Kahyaoğlu, M. (2011). Fen bilgisi öğretmen adaylarının bilgi okur-yazarlığı becerileri ile Internet kullanımına yönelik tutumları arasındaki ilişkinin değerlendirilmesi. Eğitim Teknolojileri Araştırmaları Dergisi, 2(3).

Kasowitz-Scheer, A., \& Pasqualoni, M. (2002). Information literacy instruction in higher education: trends and issues. ERIC identifier: ERD465375. Retrieved from http://surface.syr.edu/cgi/viewcontent.cgi?article $=1032 \&$ context $=$ sul

Kayri, M., ve Günüç, S. (2010). Türkiye'deki ortaöğretim öğrencilerinin Internet bağımlılık düzeyini etkileyen bazı faktörlerin karar ağaçları yöntemleri ile incelenmesi. Kuram ve Uygulamada Eğitim Bilimleri (KUYEB), 10(4), 24652500.

Konieczny, P. (2012). Wikis and Wikipedia as a teaching tool: Five years later. First Monday, 17(9).

Kurbanoğlu, S., ve Akkoyunlu, B. (2002). Öğretmen adaylarına uygulanan bilgi okuryazarlığı programının etkililiği ve bilgi okuryazarlığı becerileri ile bilgisayar öz-yeterlik algısı üzerine bir çalı̧̧ma. Hacettepe Üniversitesi Ĕgitim Fakültesi Dergisi, 22, 98-105.

Kurbanoğlu, S., Akkoyunlu, B., \& Umay, A. (2006). Developing the information literacy self-efficacy scale. Journal of Documentation, 62 (6), 730-743.

Kurt, A. A. (2010). Okuryazarlıkta dönüşümler. H.F.Odabaşı (Ed.) in Bilgi ve İletişim teknolojileri 1şı̆̆ıında dönüşümler (ss: 81-102) Ankara: Nobel Yayın Dağıtım.

Kwan, G.C.E., \& Skoric, M.M. (2013). Facebook bullying: an extension of battles in school. Computers in Human Behavior, 29(1), 16-25.

Lim, S., \& Kwon, N. (2010). Gender differences in information behavior concerning Wikipedia, an unorthodox information source? Library \& Information Science Research, 32(3), 212-220.

Lim, S. (2012). College students'credibility judgments and heuristics concerning Wikipedia. Information Processing \& Management, 49 (2), 405-419.

Tharayil, S., \& Prince-Cohen, N. (2012). High school students' perceived effect of facebook use while completing homework. In T. Amiel \& B. Wilson (Eds.), Proceedings of World Conference on Educational Multimedia, Hypermedia and Telecommunications (pp. 2665-2670). Chesapeake, VA: AACE.

Walling, D. R. (2012). Tech-Savvy Teaching and Learning Series: The Tech-Savvy Triangle. TechTrends, 56(4), 42-45.

Walton, G., \& Hepworth, M. (2012). Using assignment data to analyse a blended information literacy intervention: A quantitative approach. Journal of Librarianship and Information Science, 0(0), 1-11.

Yusof, J., Manan, N. A. A., \& Alias, A. A. (2012, December). Guided peer feedback on academic writing tasks using facebook notes: an exploratory study. 3rd International Conference on E-Learning(ICEL 2011), 67(10), 216-228. 
